\title{
Sulfato de condroitina e hialuronato de sódio no tratamento da doença articular degenerativa em cães. Estudo histológico da cartilagem articular e membrana sinovial
}

\author{
[Chondroitin sulfate and sodium hyaluronate in the treatment of the degenerative joint disease in dogs. Histological \\ features of articular cartilage and synovium] \\ E.G. Melo, V.A. Nunes, C.M.F. Rezende, M.G. Gomes, C. Malm, V.A. Gheller \\ Escola de Veterinária - UFMG \\ Caixa Postal 567 \\ 30123-970 - Belo Horizonte, MG
}

\begin{abstract}
RESUMO
Quinze cães, sem raça definida, de ambos os sexos, de peso entre 18 e $25 \mathrm{~kg}$, foram submetidos à secção artroscópica do ligamento cruzado cranial (LCCr) para indução da doença articular degenerativa (DAD). Após três semanas de instabilidade articular, o LCCr foi substituído pela fáscia lata segundo a técnica de Schwalder (1989) e os animais foram distribuídos em três grupos de cinco. Os animais do grupo I, controle, não receberam tratamento medicamentoso; os do grupo II, $24 \mathrm{mg} / \mathrm{animal}$ de sulfato de condroitina, por via IM, de cinco em cinco dias, totalizando seis aplicações; e os do grupo III foram tratados com hialuronato de sódio na dose de $20 \mathrm{mg} /$ animal, por via IV, de cinco em cinco dias num total de três administrações. Ao final de 90 dias, os animais foram eutanasiados e procedeu-se à colheita e ao processamento histológico da membrana sinovial e da cartilagem articular para avaliações morfológica e morfométrica. No grupo I foram observadas alterações degenerativas de DAD mais acentuadas que nos demais grupos, como redução do número de condrócitos, presença de pânus, fibrilações, físsuras, erosões e irregularidades na superfície articular. No grupo II observou-se elevação do número de condrócitos com aumento da atividade de síntese da matriz e redução das lesões na superfície da cartilagem. No grupo III houve aumento do número de condrócitos que eram, muitas vezes, morfologicamente inviáveis. Todos os grupos apresentaram proliferação da membrana sinovial e presença de infiltrado linfoplasmocitário na subíntima e na perivascular. Nos grupos I e III, a proliferação da membrana sinovial era exuberante com formação de pânus, presença de sinoviócitos achatados ou ausência de sinóvia com tecido de granulação. Os resultados sugerem que o sulfato de condroitina estimulou a cartilagem articular, diminuindo ou retardando as alterações da $\mathrm{DAD}$ e o hialuronato de sódio não interferiu no processo degenerativo da cartilagem articular. Não foi constatada ação favorável das drogas na membrana sinovial.
\end{abstract}

Palavras-chave: cão, doença articular degenerativa, cartilagem articular, membrana sinovial, sulfato de condroitina, hialuronato de sódio

\begin{abstract}
Fifteen mongrel dogs, both genders, weighting from 18 to $25 \mathrm{~kg}$ were used and Degenerative Joint Disease (DJD) was induced through cranial cruciate ligament (CCrL) artroscopical section. After three weeks, CCrL was reconstructed by Schawalder's (1989) technique. Then, dogs were distributed in three groups and the following protocols were used: group I, control, no other treatment but the CCrL reconstruction; group II received chondroitin sulfate $24 \mathrm{mg}$ per animal every five days, intramuscularly, in a total of six injections; and group III received sodium hyaluronate $20 \mathrm{mg}$ per animal every five days, intravenously, in a total of three injections. Clinical observation was done until 90 days after treatments. By that time, the articular cartilage and synovium were collected and their morphology was evaluated. In
\end{abstract}

Recebido em 6 de junho de 2007

Aceito em 18 de dezembro de 2007

E-mail: eliane@vet.ufmg.br

Apoio: FAPEMIG 
group I, the degenerative alterations of the DJD were the most intense. Thus, decrease of chondrocytes number, pannus, fibrillations, grooves, erosion, and irregular articular surface were observed on the cartilage. In group II, raise of chondrocytes number was observed, with increase of synthesis activity of matrix and decrease of lesions on the articular surface. There was an increase of chondrocytes in group III, but the cells were morphologically unviable. All the groups showed proliferation of the synovial membrane, with limpho-plasma cells infiltrated in subintim and perivascular. In groups I and III, the proliferation of synovium was abundant, with formation of pannus, flattened synoviocytes or synovium absent with granulation tissue. Those results suggest that the chondroitin sulfate stimulated the articular cartilage; decreasing or delaying the alterations of DJD, as well as, the sodium hyaluronate did not interfere on degenerative process in articular cartilage. No favorable action of these drugs in the synovial membrane was verified.

Keywords: dog, degenerative joint disease, articular cartilage, synovium, chondroitin sulfate, sodium hyaluronate

\section{INTRODUÇÃO}

Os eventos patológicos da osteoartrose ocorrem como resultado de diversas interações entre a cartilagem articular e tecidos adjacentes, em resposta à lesão dos condrócitos ou da matriz (Johnston, 1998). Uma vez ocorrida a lesão, inicia-se a degradação da matriz por enzimas e mediadores da inflamação. Ao mesmo tempo, os componentes da cartilagem tentam impedir a progressão da degeneração (Lipowitz, 1993). Ocorrem quebra dos proteoglicanos e da rede de colágeno, aumento da quantidade de água com conseqüente incremento do espaço entre as fibrilas colágenas, da espessura da cartilagem, necrose dos condrócitos superficiais e redução de sua densidade. $\mathrm{O}$ edema e a fibrilação da camada superficial resultam em irregularidade da superfície articular. O aumento da hidratação da cartilagem e a diluição dos proteoglicanos produzem alterações nas propriedades mecânicas da cartilagem, com perda da integridade da superfície e presença de fissuras verticais que progridem para erosões profundas e exposição do osso subcondral (Vignon et al. 1983; Lipowitz, 1993; Vaughan-Scott e Taylor, 1997). Há diminuição do conteúdo de proteoglicanos, diretamente proporcional à gravidade da doença (Lipowitz, 1993). A cartilagem reage com mecanismo compensatório, tentando impedir a progressão ou reparar o processo degenerativo (Vignon et al., 1983; Schiavinato et al., 1989; Johnston, 1997). Os condrócitos viáveis tornamse volumosos, dispostos em grupos; ocorrem hiperatividade e aumento da divisão nas camadas média e profunda; e hipertrofia da cartilagem. Portanto, coexistindo com a redução da densidade celular na camada superficial, há aumento da espessura da cartilagem (Vignon et al., 1983; Schiavinato et al., 1989). A hipertrofia da cartilagem está também associada ao aumento da síntese e da secreção dos componentes da matriz pelos condrócitos (Vignon et al. 1983; Schiavinato et al. 1989). Essas alterações podem ser acompanhadas de esclerose do osso subcondral e formação de osteófitos pericondrais (Mcllwraith, 1996).

A membrana sinovial desempenha importante papel na evolução da osteoartrose. As alterações da membrana associadas à doença articular degenerativa (DAD) variam de inflamação média à moderada e incluem hipertrofia e hiperplasia das células sinoviais, infiltração linfoplasmocitária, aumento da vascularização nos tecidos sinoviais e fibrose subsinovial (Lipowitz, 1993). A membrana libera enzimas proteolíticas no espaço articular que virão a agir na degradação da cartilagem (Vaughan-Scott e Taylor, 1997).

Uma variedade de agentes farmacológicos temse mostrado capaz de prevenir o desenvolvimento de lesões estruturais ou reduzir a progressão das alterações patológicas da osteoartrose em modelos animais (Smith et al., 1999). Os glicosaminoglicanos polissulfatados e outros agentes similares têm criado a possibilidade de tratar tais lesões (Vaughan-Scott e Taylor, 1997). Eles têm ação antiinflamatória e reduzem a perda de proteoglicanos e de colágeno, ao inibirem enzimas degradativas da cartilagem (hialuronidase, catepsina, elastase, colagenase e metaloproteinases neutras). Além disso, estimulam a síntese de proteoglicanos e colágeno, sendo capazes de aumentar a proliferação dos condrócitos e a biossíntese da matriz (Altman et al., 1989 e 1990; Francis et al., 
1989; Clark; 1991a). Esses efeitos suportam a hipótese de que as alterações da cartilagem articular, na osteoartrose, podem ser manejadas e que o uso dos glicosaminoglicanos pode complementar o tratamento da DAD (Altman et al., 1989; Clark, 1991b; Biasi et al., 2005).

O tratamento da DAD permanece controverso, pois não se conseguiu parar ou retardar o processo degenerativo de forma satisfatória. Este trabalho teve como objetivo avaliar os efeitos do sulfato de condroitina e do hialuronato de sódio, administrados por via parenteral, na morfologia da cartilagem articular e da membrana sinovial de cães com doença articular degenerativa induzida experimentalmente, como método complementar de tratamento.

\section{MATERIAL E MÉTODOS}

Foram utilizados 15 cães, sem raça definida, de ambos os sexos, de peso entre 18 e $25 \mathrm{~kg}$, provenientes do Canil de Zoonoses da Prefeitura de Belo Horizonte, MG. Os animais que se apresentaram saudáveis aos exames clínico e laboratoriais (hemograma, pesquisa de hemoparasitas e leishmaniose), e com articulações do joelho radiograficamente normais foram encaminhados para canis individuais do tipo solário, onde permaneceram e receberam ração comercial ${ }^{1}$ em quantidade sugerida pelo fabricante, durante todo o período de observação. Os animais foram submetidos à artroscopia do joelho esquerdo no qual se procedeu à primeira avaliação da cartilagem articular, seguida de desestabilização da articulação por meio da secção do ligamento cruzado cranial (LCCr), de acordo com o método de Pond eNuki (1973).

A instabilidade articular foi mantida por três semanas e, após este período, procedeu-se a novo exame artroscópico seguido de artrotomia e substituição do LCCr pela técnica intra-articular com utilização da fáscia lata segundo Schwalder (1989).

Após a substituição do ligamento, os animais foram divididos em três grupos de cinco (GI, GII e GIII). O grupo I recebeu somente tratamento cirúrgico e constituiu o controle. O grupo II recebeu $24 \mathrm{mg}$ /animal de sulfato de condroitina ${ }^{2}$

${ }^{1}$ Hill's - Colgate Palmolive S.A. - São Paulo, Brasil.

${ }^{2}$ Artroglycan - Syntex S.A. - São Paulo, Brasil. por via IM, de cinco em cinco dias, totalizando seis aplicações. O grupo III foi tratado com hialuronato de sódio $^{3}$ na dose de $20 \mathrm{mg}$ /animal, por via IV, de cinco em cinco dias, num total de três aplicações. Os protocolos de tratamento seguiram as indicações dos fabricantes. Os animais foram mantidos em canis solários individuais e observados por 90 dias.

Ao final desse período, os animais foram sacrificados com sobredose de tiopental sódico, submetidos a exame pós-morte e à colheita de material para exame histopatológico. Foram colhidas amostras da membrana sinovial, da cartilagem articular e do osso subcondral de fêmur, tíbia e patela. Foram feitas secções transversais da epífise distal e tangenciais dos côndilos medial e lateral do fêmur; cortes longitudinais da tíbia, no sentido crânio-caudal, e, transversais da patela. As amostras foram fixadas em formalina tamponada a 10\% por aproximadamente 30 dias. Aquelas que continham cartilagem e osso foram descalcificadas em ácido fórmico a $10 \%$ tamponado com citrato de sódio para $\mathrm{pH} 4,5$. A solução descalcificadora foi trocada em dias alternados até a completa descalcificação. Todas as amostras foram processadas pela técnica rotineira de inclusão em parafina. Secções de $4 \mu \mathrm{m}$ foram coradas pelas técnicas de hematoxilina e eosina e safranina $\mathrm{O}$-fast green e submetidas à histomorfometria.

Estabeleceu-se a densidade das células da cartilagem, com auxílio de ocular reticulada e observação com objetiva de aumento 40x, pela contagem do número em 30 campos/secção em 22 secções/grupo da cartilagem articular de fêmur, tíbia e patela, totalizando 660 campos/grupo. A mensuração da altura total e daquela positiva à safranina $\mathrm{O}$ foi realizada em amostras de cartilagem de fêmur, tíbia e patela coradas pela safranina O-fast green. Com auxílio de ocular micrométrica e objetiva de 10x, mediuse a altura total e a positiva à safranina $\mathrm{O}$ em três diferentes locais de cada secção. À média das três medidas foi aplicado um fator de correção obtido com auxílio de lâmina micrométrica. O número total de secções mensuradas foi de 12 por grupo. Calculou-se o índice de proporção entre a altura total e a positiva à safranina $\mathrm{O}$ pela seguinte fórmula:

${ }^{3}$ Legend - Bayer S.A. - São Paulo, Brasil. 
Índice $=$ altura total - altura corada altura total

Os dados morfométricos foram submetidos à análise de variância e a significância da comparação entre as médias foi feita pelo teste $\mathrm{t}$ de Student.

\section{RESULTADOS E DISCUSSÃO}

A avaliação histológica da cartilagem do fêmur, do platô tibial e da patela evidenciou processos degenerativos decorrentes da alteração da biomecânica da articulação femorotibiopatelar. As alterações histológicas encontradas refletiram a reação da cartilagem à instabilidade articular provocada. Reações histológicas idênticas foram observadas por McDevitt et al. (1977), Myers et al. (1990), Smith et al. (1999), que também empregaram a ruptura do $\mathrm{LCCr}$ para reproduzir experimentalmente a doença articular degenerativa e estudar seu tratamento. Os resultados confirmam que o modelo utilizado neste estudo foi eficiente para reproduzir as alterações histológicas da DAD e como meio de testar o tratamento com sulfato de condroitina e hialuronato de sódio.

As alterações mais marcantes foram observadas na cartilagem articular e eram de natureza puramente degenerativa. A camada superficial mostrava-se irregular, com sinais de fibrilação, edema e lise da matriz em todas as secções de cartilagem avaliadas, independentemente do grupo. Essas alterações são características da DAD e também foram evidenciadas por Schiavinato et al. (1989); Myers et al. (1990) e Smith et al. (1999). Com a instabilidade articular, há desequilíbrio na distribuição das forças sobre a superfície articular, levando à ruptura dos arranjos de proteoglicanos e conseqüente aumento da hidratação da cartilagem (edemaciação) com exposição das fibrilas de colágeno (fibrilação). Apesar disso, os condrócitos ainda guardavam a capacidade de proliferação e, com o aparecimento de clones celulares, tentavam a reparação da superfície articular lesada (Fig. 1C e D). Essa associação de lesões degenerativas e regenerativas foi observada por Vignon et al. (1983), que mencionaram ser a hipertrofia da cartilagem um evento inicial da osteoartrite induzida pela instabilidade articular. Isso demonstra a capacidade de remodelação do tecido em resposta ao estresse mecânico anormal. Porém, o processo regenerativo foi limitado, principalmente nos grupos I e II, uma vez que não ocorreu reposição significativa do tecido lesado.

Nos animais tratados com sulfato de condroitina e hialuronato de sódio, a cartilagem apresentou acentuada hipocelularidade ou, mesmo, ausência da camada superficial. Isso foi observado por Vignon et al. (1983), Schiavinato et al. (1989), e Marshall e Chan (1996), que consideraram a redução da densidade de condrócitos na camada superficial da cartilagem como lesão precocemente detectada pela análise histológica em animais submetidos à instabilidade articular. Dessa forma, poder-se-ia supor que as drogas utilizadas retardem o processo degenerativo. Entretanto, perda de basofilia da matriz, vacuolização, picnose ou necrose de condrócitos, fissuras e erosões da superfície da cartilagem também foram alterações marcantes no grupocontrole, bem como no tratado com hialuronato de sódio (Fig. 1B-D). Esses resultados demonstram que, nos grupos I e III, o processo degenerativo era morfologicamente mais acentuado e avançado, quando comparado ao grupo II. A cartilagem articular dos animais desse grupo apresentava, na maioria das vezes, camada superficial celularizada e aumento da densidade celular nas camadas média e profunda. Os condrócitos apresentavam-se dispostos de forma colunar com aumento da basofilia da matriz extracelular. Esses achados refletem hiperatividade dos condrócitos e divisão celular, mimetizando o retorno da cartilagem ao crescimento (Fig. 1A). A superfície articular estava mais regular, com poucas áreas de fibrilação e edema. $\mathrm{O}$ tratamento, portanto, com sulfato de condroitina pareceu minimizar ou retardar a evolução de lesões degenerativas da cartilagem. Esses resultados são coincidentes com os de Altman et al. (1989) e Francis et al. (1989), os quais sugeriram que os glicosaminoglicanos polissulfatados alteram a evolução da osteoartrose. O mecanismo, porém, que leva os condrócitos a se proliferarem e aumentarem sua síntese e secreção ainda não foi estabelecido, merecendo mais estudos sobre a ação dos glicosaminoglicanos exógenos na cartilagem articular.

Outro aspecto marcante evidenciado pela análise morfológica da cartilagem nos grupos I e III foi a 
existência de camadas de células fibrosas sobre a superfície articular, sempre associadas a desaparecimento da camada cartilaginosa superficial, aumento da celularidade e necrose de células nas camadas mais profundas. Ao contrário, Schiavinato et al. (1989) afirmaram que o hialuronato de sódio inibe a formação da camada fibroblástica, com redução da lesão degenerativa da cartilagem.

A proliferação do tecido conjuntivo e sua aderência à superfície da cartilagem é um fenômeno freqüente nas artrites e tem sido referida como pânus ou tecido especial de granulação. Na DAD, embora as lesões sejam originalmente degenerativas, há o desenvolvimento de fenômenos inflamatórios a partir dos tecidos intra e periarticulares. De acordo com Fassbender et al. (1983), citado por Schiavinato et al (1989), a formação do pânus é precedida por proliferação de células mesenquimais originadas da membrana sinovial sobre a cartilagem. Nos estágios subseqüentes, há crescimento e diferenciação progressiva do pânus, o que pode contribuir para a lesão da cartilagem. Outra hipótese sobre o aparecimento do pânus, citada por Schiavinato et al. (1989), é a possibilidade dos condrócitos superficiais se transformarem em fibroblastos em resposta a alterações do ambiente celular.

No grupo III também houve proliferação acentuada da membrana sinovial, com formação de tecido de granulação denso (pânus) que recobriu a superfície articular, levando à degeneração da cartilagem (Fig. 1B). Como citado por Allard et al. (1990), as células inflamatórias que se acumulam neste tecido sinovial proliferado podem induzir lesão articular pela produção de enzimas proteolíticas e pela interação, via citocinas, com células da cartilagem e do osso. Shiozawa et al. (1983) determinaram que as principais células que participam da destruição da cartilagem na junção pânus-cartilagem são as células semelhantes a fibroblastos e macrófagos. Nas áreas de inserção da membrana sinovial observou-se acentuada diferenciação tecidual em fibrocartilagem, com neoformação óssea, determinando o aparecimento de osteófitos marginais. Foi possível observar também esclerose do osso subcondral, já citada por Mcllwraith (1996) como característica da DAD.

A osteofitose periarticular foi outra alteração observada tanto no grupo-controle quanto no tratado com hialuronato de sódio. Os osteófitos originaram-se da metaplasia da membrana sinovial ou diretamente do periósteo. Parece que a junção entre o tecido sinovial, a cartilagem e o osso é de fundamental importância na formação dos osteófitos. Eles estão freqüentemente associados ao agravamento da osteoartrose, apesar de Smith et al. (1999) considerarem que possam representar resposta apenas à instabilidade articular e que seu número ou tamanho não, necessariamente, refletem a gravidade das alterações da DAD. Mas, como citado por Vignon et al. (1983), eles parecem indicar que o processo de reação ao estresse anormal não está confinado à cartilagem articular, mas também às estruturas adjacentes.

Os dados morfométricos obtidos da cartilagem articular, ou seja, número de células e proporção da cartilagem positiva à safranina-O foram coerentes com os achados morfológicos.

$\mathrm{O}$ número de condrócitos da cartilagem articular dos grupos II e III foi semelhante entre si e significativamente maior $(\mathrm{P}<0,001$ e $\mathrm{P}<0,01$, respectivamente) em relação ao grupo I (Tab.1). $\mathrm{O}$ aumento do número de células, mesmo com redução da densidade celular na superfície articular é determinado pela divisão dos condrócitos nas zonas média e profunda em resposta ao estresse anormal causado pela instabilidade articular (Vignon et al., 1983). Nos grupos II e III, porém, a proliferação de condrócitos foi significativa. No caso do hialuronato de sódio, apesar do número elevado de condrócitos, muitos pareciam inviáveis, apresentando citoplasma vacuolizado, núcleos picnóticos e outros necróticos, como mencionado anteriormente. Já no grupo tratado com sulfato de condroitina, a elevada densidade celular foi acompanhada de aumento da altura da cartilagem e os condrócitos mostravam-se ativos e responsivos à lesão da DAD. Achados similares foram observados por Francis et al. (1989), os quais sugeriram que os glicosaminoglicanos polissulfatados aumentam a mitose celular da cartilagem. 

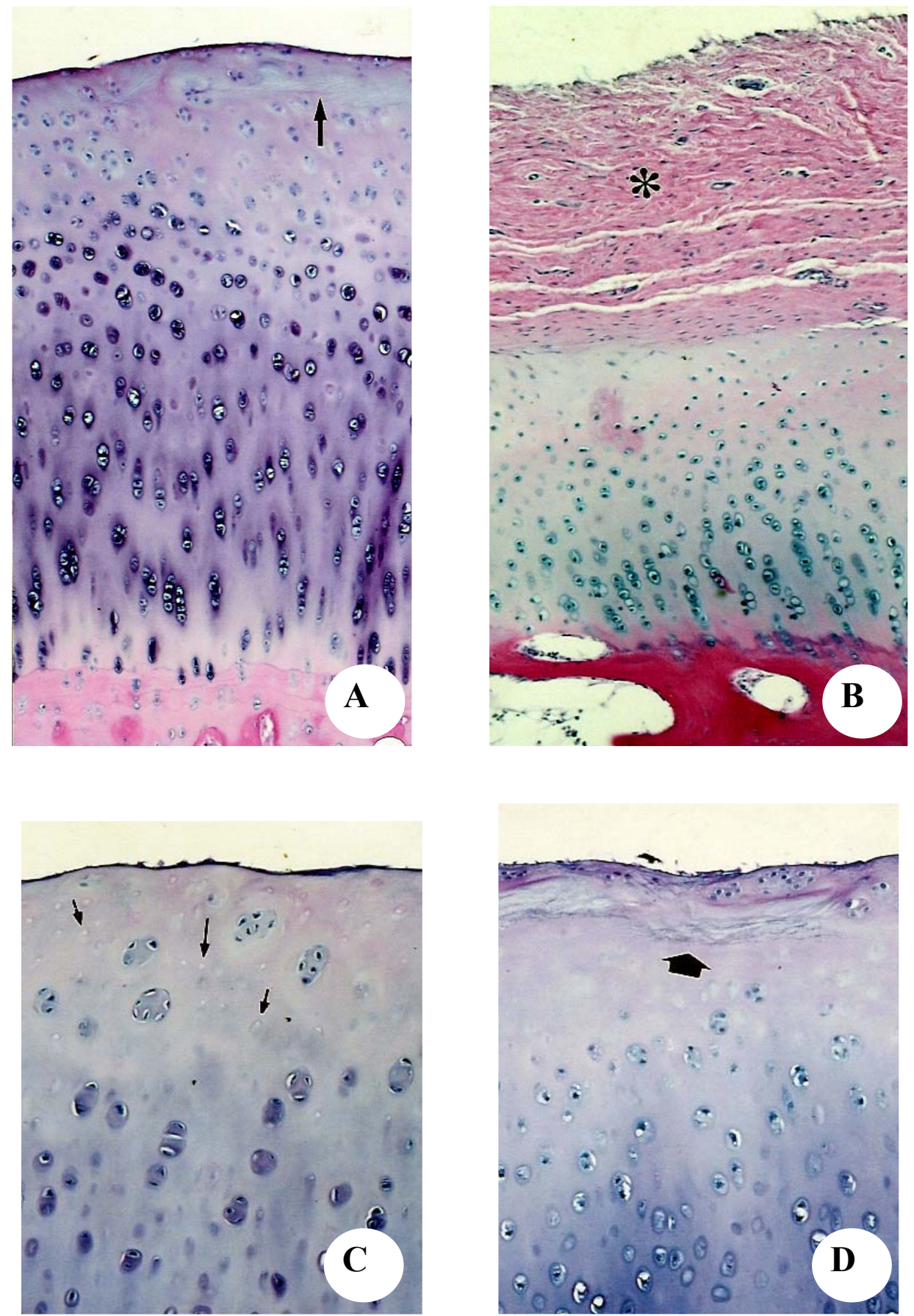

Figura 1. Secções de cartilagem articular com alterações degenerativas da osteoartrose e coradas pela HE. A) Aumento da celularidade nas camadas média e profunda com fibrilação da camada superficial (seta), proliferação celular e condrócitos dispostos de forma colunar. Patela de animal tratado com sulfato de condroitina $(107,1 x)$. B) Tecido de granulação sobre a superfície articular (asterisco) com degeneração da cartilagem. Patela de animal tratado com hialuronato de sódio $(115,7 \mathrm{x})$. C) Ausência da camada superficial, necrose de condrócitos (setas) e perda de basofilia da matriz. Patela de animal tratado com hialuronato de sódio $(133,7 x)$. D) Fibrilação (seta) e proliferação de condrócitos da camada superficial. Fêmur de animal do grupo-controle $(133,7 x)$. 
Tabela 1. Número médio e desvio-padrão de condrócitos na cartilagem articular de cães com doença articular degenerativa tratados ou não com sulfato de condroitina e hialuronato de sódio

\begin{tabular}{lcc}
\hline Grupos & $\mathrm{N}^{\circ}$ de condrócitos & $\mathrm{P}$ \\
\hline Controle & $33,77 \pm 11,02 \mathrm{a}$ & $\mathrm{P}>0,05$ \\
Sulfato de condroitina & $47,24 \pm 9,94 \mathrm{~b}$ & $\mathrm{P}<0,001$ \\
Hialuronato de sódio & $45,32 \pm 11,53 \mathrm{~b}$ & $\mathrm{P}<0,01$ \\
\hline
\end{tabular}

Os valores representam o valor médio \pm desvio-padrão de diferentes secções de cartilagem por articulação. Letras diferentes nas colunas representam diferenças significativas.

Quanto à altura total da cartilagem e à altura positiva à safranina $\mathrm{O}$, não houve diferença significativa entre os grupos (Tab. 2), apesar da tendência de serem maiores no grupo II. Ao se relacionar o aumento do número de condrócitos a essas variáveis, pode-se inferir que o sulfato de condroitina estimulou os condrócitos a se proliferarem e a produzirem matriz extracelular, o que determinou o aumento do número de células e da altura da cartilagem. Além disso, as células demonstraram-se responsivas ao tratamento, aumentando a atividade sintética e secretora de glicosaminoglicanos, tal como evidenciado pela altura da cartilagem positivamente corada pela safranina O (Fig. 2). Altman et al. (1989) e Francis et al. (1989) também afirmaram que os glicosaminoglicanos polissulfatados aumentam a capacidade biossintética da cartilagem articular. Schiavinato et al. (1989), no entanto, consideraram tal fato aceitável em articulações com osteoartrose avançada e que os condrócitos viáveis tornem-se volumosos e com grande número de organelas, sugerindo aumento das atividades de síntese e secreção.

Tabela 2. Alturas total e positiva à safranina $\mathrm{O}$ e índice proporcional ao conteúdo de proteoglicanos da cartilagem articular de cães com DAD, por tratamento

\begin{tabular}{lcccc}
\hline Grupos & Altura total & Altura safranina & Índice & $\mathrm{P}$ \\
\hline Controle & $664,4 \pm 292,4 \mathrm{a}$ & $489,4 \pm 260,1 \mathrm{a}$ & $0,28 \pm 0,12 \mathrm{a}$ & $\mathrm{P}>0,05$ \\
Sulfato de condroitina & $750,8 \pm 221,7 \mathrm{a}$ & $621,7 \pm 163,3 \mathrm{a}$ & $0,16 \pm 0,01 \mathrm{~b}$ & $\mathrm{P}<0,05$ \\
Hialuronato de sódio & $710,0 \pm 233,2 \mathrm{a}$ & $535,1 \pm 198,4 \mathrm{a}$ & $0,26 \pm 0,07 \mathrm{a}$ & $\mathrm{P}>0,05$ \\
\hline
\end{tabular}

Os valores representam o valor médio \pm desvio-padrão de diferentes secções de cartilagem por articulação. Letras diferentes nas colunas representam diferenças significativas pelo teste t de Student.

Apesar do aumento significativo do número de condrócitos, o hialuronato de sódio não determinou elevação expressiva da altura da cartilagem total ou corada pela safranina O. Isso poderia ser explicado pela inviabilidade da maioria dos condrócitos, já mencionada, que determinou baixa atividade de síntese da matriz extracelular. $\mathrm{O}$ aumento do número de condrócitos, neste grupo, foi tipicamente zonal e, principalmente, nos locais com extensas lesões da camada superficial, características semelhantes às do grupo-controle. Já com o sulfato de condroitina, o aumento do número de células foi distribuído de forma homogênea por toda a cartilagem articular.

Ao se calcular o índice de proporção entre a altura total da cartilagem e a da positiva à safranina $\mathrm{O}$, observou-se no grupo II que $\mathrm{o}$ índice foi estatisticamente menor $(p<0,05)$ do que nos demais grupos (Tab. 2). Portanto, a quantidade de cartilagem marcada pela safranina O é proporcionalmente maior. Sendo a safranina
O um corante com afinidade específica para polissacarídeos, o resultado sugere que os condrócitos eram ativos e sintetizaram os glicosaminoglicanos da matriz em proporção maior do que nos demais grupos. O maior conteúdo de glicosaminoglicanos associado ao aumento da síntese da matriz também foi visto por Vignon et al. (1983) na hipertrofia da cartilagem e foi relacionado ao aumento da síntese de matriz. No grupo III, o índice foi similar ao do grupo I, isso provavelmente pela inviabilidade funcional dos condrócitos em sintetizar e secretar os componentes da matriz, também evidenciado pela diminuição da basofilia da cartilagem.

Para melhorar a eficiência da análise estatística na busca de diferenças entre os grupos quanto à altura da cartilagem total e a corada pela safranina $\mathrm{O}$, talvez fosse necessário um número maior de amostras ou que a avaliação fosse feita em cada osso separadamente. 


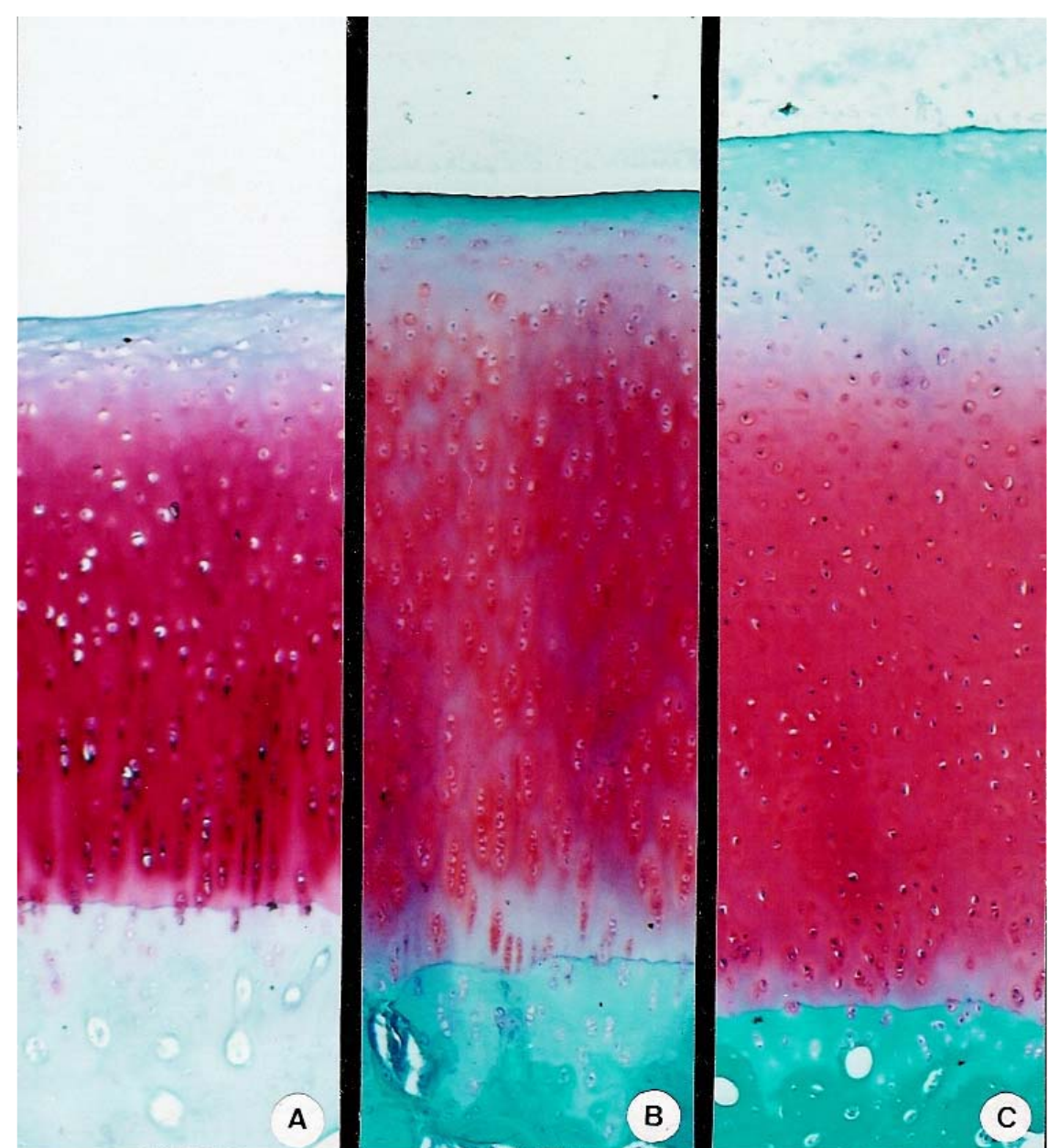

Figura 2. Secções da cartilagem articular de patela demonstrando diferenças na proporção de coloração da matriz extracelular pela safranina O- fast green $(85,7 \mathrm{x})$. A) Animal do grupo-controle. B) Animal tratado com sulfato de condroitina. C) Animal tratado com hialuronato de sódio.

A morfologia da membrana sinovial, independente do tratamento, variou conforme a região observada. Notaram-se áreas em que a proliferação da membrana foi acentuada, com as vilosidades formando grandes projeções em forma de língua, revestidas por camada hiperplásica de sinoviócitos (íntima). O tecido conjuntivo frouxo subintimal (areolar) foi substituído por tecido de granulação (conjuntivo fibroso proliferado e proliferação vascular), com presença de células inflamatórias, principalmente plasmócitos, distribuídas difusamente ou em focos disseminados. Em outras regiões, a sinóvia era delgada, com no máximo duas a três camadas de sinoviócitos morfologicamente bem caracterizados, revestindo tecido conjuntivo denso com poucas células inflamatórias, a maioria com distribuição perivascular. Esses achados coincidem com os de Zorn e Carneiro (1987), os quais já haviam observado a existência de variações morfológicas zonais (regionais) da membrana sinovial. Essas variações estariam provavelmente relacionadas à diferença de incidência e distribuição das forças sobre a articulação. Assim, é recomendável, em qualquer avaliação histológica das doenças articulares, a análise de várias secções da membrana sinovial de uma mesma articulação, como foi realizado neste estudo.

A membrana sinovial dos animais do grupo II apresentou aspectos semelhantes aos da do grupocontrole. Algumas áreas apresentavam hiperplasia das vilosidades, criando projeções papilares. O tecido areolar mostrou-se desorganizado, com separação (edema) e degeneração de fibras colágenas. Observou-se proliferação de tecido de granulação denso e intensamente vascularizado, infiltrado linfoplasmocitário na camada subintimal na base das vilosidades hiperplásicas e que permeam o tecido de granulação. Em algumas áreas, as células inflamatórias formaram 
aglomerados, com linfócitos centrais contornados por várias camadas de plasmócitos, que mimetizava nódulos linfóides. Os sinoviócitos apresentaram-se morfologicamente normais (Fig. 3D). Esse quadro não difere do encontrado por Galloway e Lester (1995) em cães com ruptura do LCCr, refletindo a reação da membrana sinovial ao processo degenerativo da articulação. Os mesmos autores afirmaram que o tempo é fator determinante para o aparecimento da reação. No presente estudo, a instabilidade articular foi mantida por 21 dias e, mesmo com a correção posterior e o uso de um agente considerado antiinflamatório, não foi possível reverter a resposta inflamatória da membrana sinovial.

Nos animais do grupo III, os sinoviócitos apresentaram perda de sua característica
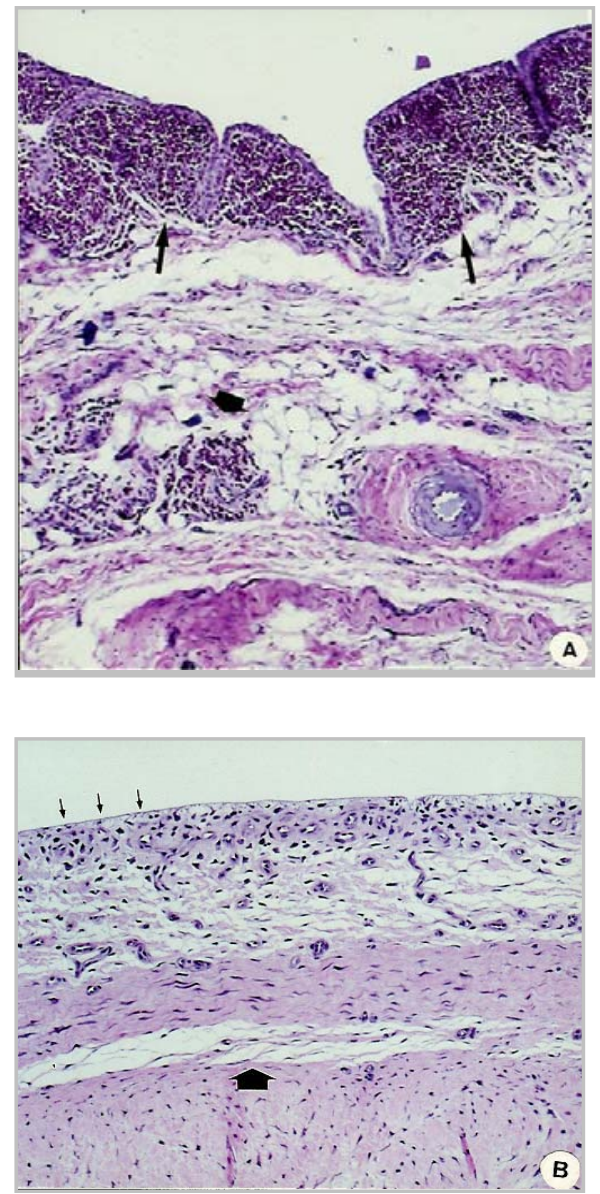

Figura 3. Secções de membrana sinovial coradas pela HE. A) Infiltrado inflamatório subintimal denso (setas finas), edema e infiltrado perivascular (seta larga) $(107,1 \mathrm{x})$. Animal tratado com hialuronato de sódio. B) Ausência de sinóvia (setas finas) e edema (seta larga) (111,3x). Animal tratado com hialuronato de sódio. C) Infiltrado inflamatório subsinovial, tecido de granulação (asterisco) e edema (seta) $(107,1 \mathrm{x})$. Animal tratado com hialuronato de sódio. D) Proliferação, infiltrado inflamatório em forma de nódulos (setas) e degeneração do tecido conjuntivo. Animal tratado com sulfato de condroitina $(42,8 \mathrm{x})$. morfológica, tornando-se achatados e muito semelhantes a fibrócitos maduros e, em algumas áreas, chegaram a desaparecer (ausência da íntima) (Fig. 3B). O infiltrado linfoplasmocitário esteve presente e foi muito denso na subíntima, assemelhando-se a órgãos linfóides com formação de septos conjuntivos entremeando e separando as células (Fig. 3A e C). Havia, ainda, tecido de granulação denso com intensa proliferação vascular e infiltrado perivascular (Fig. 3A e C). Em cães submetidos à secção do $\mathrm{LCCr}$ e mantidos com instabilidade articular por oito a 13 semanas, sem qualquer recurso terapêutico, a membrana sinovial mostrou as mesmas características (Lipowitz et al., 1985). Assim, conclui-se que o hialuronato de sódio tem pouca ação sobre a reação inflamatória da membrana sinovial, além de provocar reações involutivas dos sinoviócitos (Fig. 3B).
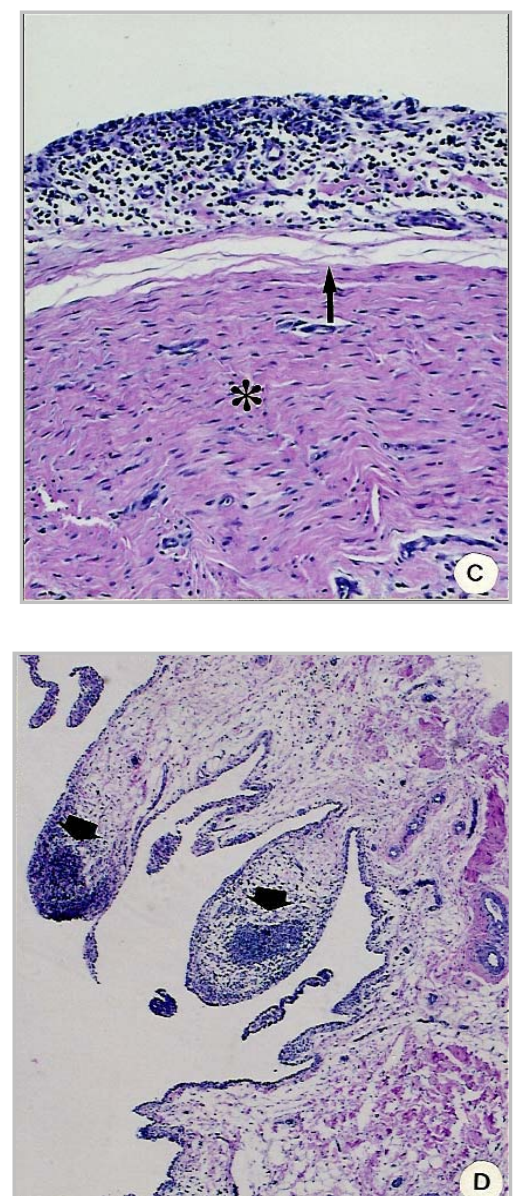
As características da reação inflamatória da membrana, com presença de aglomerados linfoplasmocitários que formam nódulos e infiltram o espaço perivascular, sugerem reação imunomediada na DAD, o que já foi aventado por Lipowitz et al. (1985) e Galloway e Lester (1995).

Pode-se concluir, portanto, que as alterações da membrana sinovial no grupo-controle são idênticas ou mais discretas do que nos grupos tratados, e isto sugere que apenas a estabilização da articulação com a substituição do LCCr pode ser suficiente para induzir a reparação da membrana sinovial

Com isso, é possível que a reparação completa da membrana sinovial seja possível apenas se eliminado o componente imunológico da reação, sob pena de haver perpetuação do processo inflamatório, com todas as sabidas conseqüências danosas sobre a articulação. Assim, mesmo que se consiga reverter as alterações da cartilagem articular, torna-se necessário reverter a reação da membrana sinovial para se conseguir total reparação da articulação.

\section{REFERÊNCIAS BIBLIOGRÁFICAS}

ALLARD, S.A.; BAYLISS, M.T.; MAINI, R.N. The sinovium-cartilage junction of the normal human knee. Arth. Rheum., v.33, p.170-1178, 1990

ALTMAN, R.D.; DAVID, D.D.; MUNIZ, O.E. et al. Therapeutic treatment of canine osteDADrthritis with glycosaminoglycan polyssulfuric acid ester. Arth. Rheum., v.32, p.759-765, 1989

ALTMAN, R.D.; DAVID, D.D.; MUNIZ, O.E. et al Prophylatic treatment of canine osteoarthritis with glycosaminoglyxan polyssulfuric acid ester. Arth. Rheum., v.32, p.759-765, 1990

BIASI, F.; RAHAL, S.C.; VOLPI, J.L. et al. Reconstrução do ligamento cruzado em cães, associado ou não ao sulfato de condroitina. Arq. Bras. Med. Vet. Zootec., v.57, p.442-447, 2005 .

CLARK, D.M. Current concepts int the treatment of degenerative joint disease. Comp. Cont. Educ. Pract. Vet., v.13, p.1439-1446, 1991.

FASSBENDER, H.G. histomorphological basis of articular cartilage destruction in rheumatoid arthritis. Collagen Rel. Res., v.3, p.141-155, 1983.

FRANCIS, D.J.; FORREST, M.J.; BROOKS, P.M. et al. Retardation of articular cartilage degradation by glycosaminoglycan polysulfate, pentosan polyssulfat, and DH-40J in the rat air pouch model. Arth. Rheum., v.32, p.608-616, 1989 .
GALLOWAY, R.H.; LESTER, S.J. Histopathological evaluation of canine stifle joint synovial membrane collected at the time or repair of cranial cruciate ligamente rupture. $J$. Am. Anim. Hosp. Assoc., v.31, p.289-294, 1995.

JOHNSTON, S.A. osteoarthritis: Articular anatomy, phisiology and pathology. In: JOHNSTON, S.A. (Ed). osteoarthritis. Vet. Clin. North Am. Small Anim. Pract., v.27, p.699-723, 1997.

LIPOWITZ, A.J. Synovial fluid. In: NEWTON, C.D.; NUNAMAKER, D.M. (Eds), Textbook of Small Animal. Orthopaedics. Philadelphia: J.B. Lippincott, 1985. p.10151028

LIPOWITZ, A.J. Degenerative joints diseases. In: SLATTER, D. (Ed). Textbook of Small Animal. Surgery. 2.ed. Philadelphia: W. B. Saunders, 1993. p.1921-1927.

MARSHALL, K.W.; CHAN, A.D.M. Bilateral canine model of osteoarthritis. J. Rheum., v.23, p.344-350, 1996.

McDEVITT, C.; GILBERTTSON, E.; MUIR, H. An experimental model of osteoarthritis; early morphological and biochemical changes. J. Bone Joint Surg., v.59b, p.24-34, 1977.

McLLWRAITH, CW. General pathobiology of the joint and response to injury. In McLLWRAITH, CW.; TROTTER, GW. (Eds). Joint Disease in the Horse. Philadelphia: W.B. Saunders. p.40-80, 1996.

MYERS, S.L.; BRANT, K.D.; ALBRECHT, M.E. Synovitis and osteoarthritic changes in caninearticular cartilage after anterior cruciate ligament transection. Arth. Rheum., v.33, p.1406-1415 1990.

POND, M.J.; NUKI, G. Experimentally-induced osteoarthritits in the dog. Ann. Rheum. Dis., v.32, p.387, 1973

SCHIAVINATO, A.; LINI, E.; GUIDOLIN, D. et al. Intraarticular sodium hyaluronate injections in the Pond-Nuki experimental model of osteoarthritis in dogs: IImorphological findings. Clin. Orthop. Relat. Res., v.241, p.286-299, 1989.

SCHWALDER. P. Eigene methoden zur operativen rekonstruktion bei rupturen des voederen und hinteren krenzbandes. Kleinterpraxis, v.7, p.323-330, 1989

SHIOZAWA, S.; SHIOZAWA, K.; FUJITA, T. Morphologic observations in the esarly phase of the cartilage-pannus junction. Arth. Rheum., v.26, p.472-478, 1983

SMITH JR., G.N.; MYERS, S.L.; BRANDT, K.D. et al. Diacerhein treatment reduces the severity of osteoarthritis in the canine cruciate-deficiency model of osteoarthritis. Arth. Reum., v.42, p.545-554, 1999.

VAUGHAN-SCOTT, T.; TAYLOR, J.H. The pathophysiology an medical manegement of canine osteoarthritis. J. S. Afr. Vet. Assoc., v.68, p.21-25, 1997.

VIGNON, E.; ARLOT, M.; HARTMAN, D. et al. Hypertrophic repair of articular cartilage in experimental osteoarthrosis. Ann. Rheum. Dis., v.42, p.82-88, 1983.

ZORN, T.M.; CARNEIRO, J. Cell proliferation in synovial membrane of Young mice. Acta Anat., v.128, p.19-22, 1987. 